\title{
Development of positive/negative pressure booth generating airflow for protection of medical staff from contagious respiratory pathogens
}

\author{
Hidekazu Nishimura ${ }^{1}$, Soichiro Sakata ${ }^{2}$ \\ ${ }^{1}$ Virus Research Center, Clinical Research Division, Sendai Medical Center, National Hospital Organization, Sendai, Japan; ${ }^{2}$ Mediair Japan Inc., \\ Yokohama, Japan \\ Contributions: (I) Conception and design: All authors; (II) Administrative support: H Nishimura; (III) Provision of study materials or patients: S \\ Sakata; (IV) Collection and assembly of data: All authors; (V) Data analysis and interpretation: All authors; (VI) Manuscript writing: All authors; (VII) \\ Final approval of manuscript: All authors. \\ Correspondence to: Hidekazu Nishimura. 2-11-12 Miyagino, Miyagino, Sendai 983-8520, Japan. Email: hide-nishimura@mte.biglobe.ne.jp.
}

\begin{abstract}
Background: The pandemic of COVID-19 caused confusion in medical settings because of increased patient load, and caused many infections among medical staff which occurred through exposure to bioparticles discharged from patients. The risk of exposure became maximum at the examination of patients, particularly in the collection of respiratory specimens. Effective interventions to reduce the risk are needed.

Methods: A one-person booth consisting of curtain walls, frames, and fan-HEPA filter-unit (FFU) was designed. Using the airstream from/to FFU, it has dual functions as a positive/negative pressure machine to prevent pathogens in patient's cough to reach the medical staff inside/outside the booth, respectively. The curtain walls and positioning of the patient and staff were aerodynamically optimized for the best control of the airstream.

Results: The positive pressure booth is to isolate a staff inside to safely deal with a surge in the number of patients in situations like influenza pandemics. The negative pressure booth is to isolate a patient inside to protect a staff outside from dangerous contagious respiratory infectious diseases including COVID-19. A calculated airflow of the positive pressure machine efficiently pushed back bio-particles discharged from a person outside the booth. The bio-particles of a cough from a person inside the negative pressure booth was sucked into the FFU for filtration immediately after the discharge. The booth needed a short front curtain of a stair-cut shape, and a patient and a staff facing each other needed to be positioned at an angle $45^{\circ}$ to the airstream for optimization of the airflow.

Conclusions: The booth named Barriflow ${ }^{\circledR}$ would prevent the bioparticles of a patient's cough to reach the medical staff due to an aerodynamically designed airstream from the FFU and curtains surrounding it. It could be applied to cases of not only COVID-19 or influenza but also of other dangerous, contagious respiratory diseases.
\end{abstract}

Keywords: Airborne transmission; negative pressure booth; positive pressure booth; cough; airflow

Submitted Apr 09, 2020. Accepted for publication Aug 11, 2020.

doi: $10.21037 /$ jtd-20-1607

View this article at: http://dx.doi.org/10.21037/jtd-20-1607

\section{Introduction}

In every winter in temperate zones as well as in a pandemic situation, hospitals are often overflowed with influenza patients. These situations are inevitably associated with a risk of nosocomial airborne/aerosol infections (1-6), particularly in out-patient clinics and/or emergency units of hospitals $(7,8)$.

The risk is augmented in outbreaks by more pathogenic 

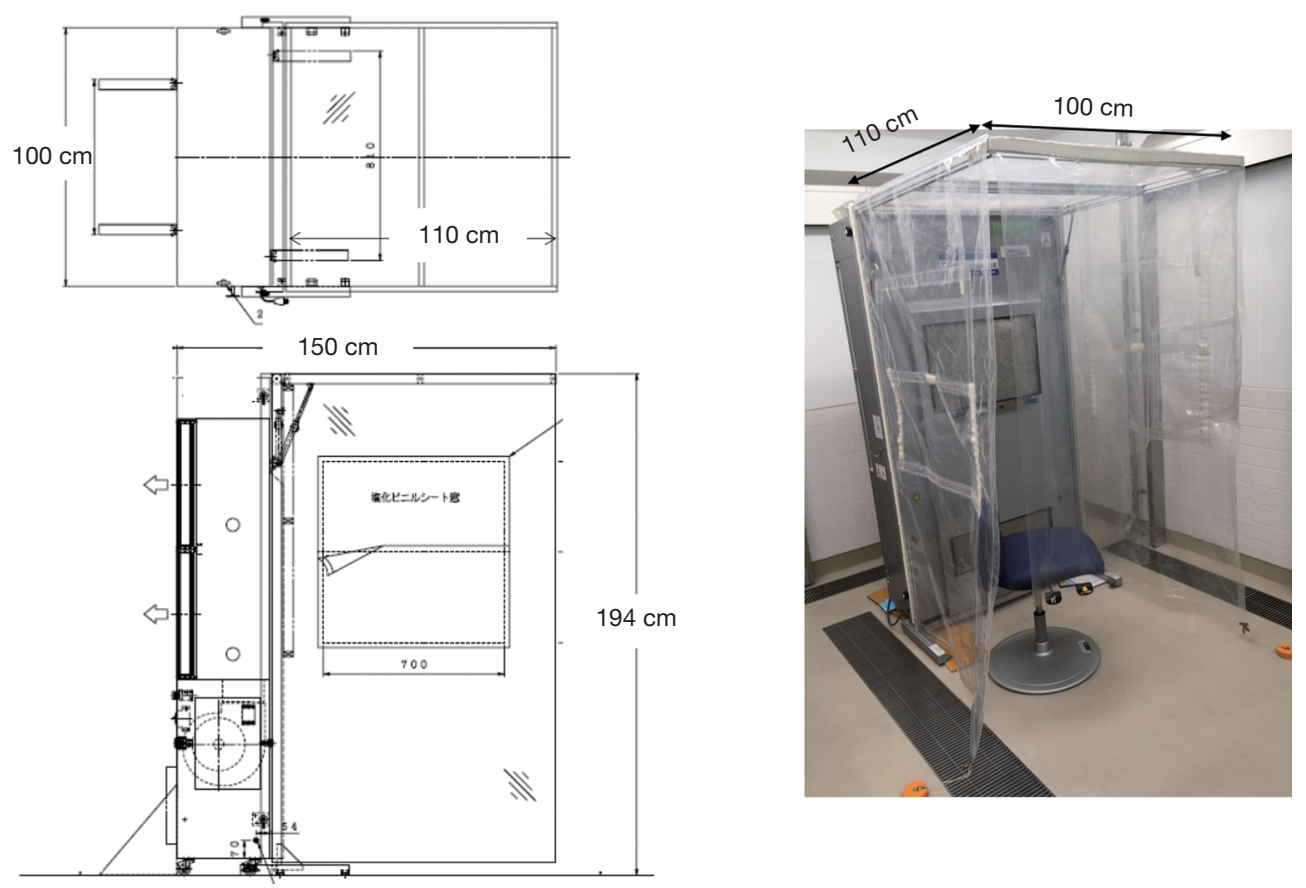

Figure 1 Structure and dimension of Barriflow ${ }^{\circledR}$. The Barriflow ${ }^{\circledR}$ is a booth consisting of a large sized fan-HEPA filter-unit (FFU), plastic curtain walls and foldable curtain frames. Its dimensions at the time it is ready for use are shown.

airborne infections such as severe acute respiratory syndrome (SARS) in several countries in 2003 (9), Middle East respiratory syndrome (MERS) in middle east countries and Korea in 2015 (10,11), COVID-19 pandemic $(12,13)$, avian and other zoonotic influenza cases (14), as well as cases of unknown stage of emerged contagious respiratory diseases caused by viruses. Besides these exotic pathogens, medical settings sometimes face a classical but still a great threat of tuberculosis including multi-drug resistant ones (15).

The risk of nosocomial airborne/droplet exposure becomes high and medical staff needs maximum caution during medical procedures for patients, like collection of nasopharyngeal/pharyngeal swab or sputum and during tracheal suctioning (16), in which aerosol particles are induced. Thus, interventions that reduce such risk and protect the medical staff are needed.

Use of personal protective equipment (PPE) such as face masks (17), and frequent ventilation (18-20) with or without stand-alone room air filtration units or air-cleaners were reported (21). However, N95 respirator masks recommended for medical staff use as a personal protective gear (22) are laborious in general in maintaining fitness for a long time and sometimes lose the fitness, and it is inevitable for patients that they take it off during specimen collection; ventilation with small stand-alone room air filtration units or air-cleaners takes a long time for exchange of total room air; and opening windows is not practical in the winter cold season and impossible for rooms without windows.

In this paper, we offer an alternative option with a machine that protects a medical staff treating a patient. The staff is not exposed to the bioparticles from the coughing patient due to an airstream from/to the fan-HEPA filterunit (FFU) and curtains surrounding it, which are designed based on aerodynamic analyses of cough particles (23) to control the stream to prevent the bioparticles from reaching the staff.

\section{Methods}

The booth system measuring $100 \mathrm{~cm} \mathrm{~W} \times 150 \mathrm{~cm} \mathrm{~L} \times 194$ $\mathrm{cm} \mathrm{H}$ consisted of a large sized FFU with strong airflow of $30 \mathrm{~m}^{3} / \mathrm{min}$ (VEF-25-S, Japan Vilene Company, Ltd., Tokyo, Japan) and side curtain walls with a roof made of transparent plastic sheet sustained by frames (Figure 1, Figure S1). The booth was designed to perform two functions according to the direction of the airflow by changing the setting side of the curtain walls to the FFU (Figure S2). As a positive pressure booth machine, the airflow generated by the FFU 
and the curtains draped from the roof sheet to the floor make a stable air stream to the exit and prevent the bioparticles containing pathogens carried by a patient's cough to come inside and remain there. As a negative pressure booth machine, a strong airstream is made toward the FFU and prevent patient's cough going outside.

The performance of the booth was examined according to four design parameters: (I) the booth has no front curtain; (II) the booth has a short front curtain at the exit, and a dummy is placed inside the booth simulating a medical staff sitting directly straight to the air stream line or (III) the dummy is sitting at $45^{\circ}$ angle to the stream line; (IV) the booth has a different front curtain shape. Airstreams inside the booth from/to the FFU were aerodynamically analyzed in each design to optimize the booth's functions.

\section{Physical analyses}

The air speed was measured using an ultrasonic 3D anemometer for clean room (WA-590, Sonic Corporation Tokyo, Japan) or an anemometer (model 6141, KANOMAX Japan Inc., Osaka, Japan). The airflow rate was obtained from the formula, "air speed $\times$ opening area". The positive pressure inside the hood was measured with a fine differential pressure gauge (DPC-500N12, Okano Works. Ltd., Osaka, Japan).

\section{Visualization of airflow from/to the FFU and movement of cigarette smoke substituting for bio-particles generated by a cough}

The smoke was generated from nozzles set vertically at the abdomen and chest of the dummy in the laminar airflow from the FFU or from the back side of the dummy or the front curtain attachment site in the airflow to the FFU. Bio-particles generated by a cough was substituted with that of cigarette smoke. A male smoker volunteer in his $30 \mathrm{~s}$ inhaled one breath of cigarette smoke and made a voluntary cough in front of the booth entrance about 20$30 \mathrm{~cm}$ distant from the curtain toward the dummy. The movement of the smoke exhaled with cough was taken and recorded by a digital video system (nac Image Technology Inc., Tokyo, Japan). The air was sampled at the dummy's neck under the chin as a representative monitoring site close to the face area to count the particles that reached there. The monitoring was performed for two minutes, being sufficient for monitoring particles from other areas in the booth.

\section{Measuring of the cough or cigarette smoke particles}

In the leakage tests of particles of the cough or of the cigarette smoke substituting for the cough, the particle concentration in the air was measured in a class 2 cleanroom conforming to ISO 14664-1. The air was sampled at the neck under the chin of the dummy set at about 20 $30 \mathrm{~cm}$ distant from the site where the front curtain was set, and concentration of particles of size-range over $0.3 \mu \mathrm{m}$ was measured with a laser particle counter (KC-03, Rion Co., Ltd., Tokyo, Japan).

\section{Results}

The booth is designed for dual use as a positive and a negative pressure machine and easily convertible between them (Figure S2). The former is aimed to isolate and protect a medical staff who is on duty in dealing with a surge of patients in situations like influenza pandemics, and the latter is to isolate a patient inside to protect the staff outside, which can be applied to COVID-19 cases, as well as other cases of dangerous, contagious respiratory infectious diseases like avian influenza and multi-drug resistant tuberculosis.

\section{Positive pressure machine use}

\section{Performance of FFU}

The airflow rate of the FFU adopted to the booth was $30 \mathrm{~m}^{3} / \mathrm{min}$ as it was the maximum rate among commercially available FFUs at the time of development. The exit area of the FFU was shaped as a square of $1 \mathrm{~m} \times$ $1 \mathrm{~m}$, and it was set at $75-175 \mathrm{~cm}$ above the floor (Figure $2 A$ ). We measured horizontal velocities of the airflow toward the $\mathrm{FFU}(\mathrm{Y} \mathrm{cm} / \mathrm{s})$ generated at a distance of $5 \mathrm{~cm}$ from it and at heights of 20,40,60, and $80 \mathrm{~cm}$ from the floor (Z), 20, 40, 60, and $80 \mathrm{~cm}$ from the left end of FFU (X), and found that the velocities were almost homogenous among the measuring points, $55 \pm 5 \mathrm{~cm} / \mathrm{s}$ toward the exit, except $45-50 \mathrm{~cm} / \mathrm{s}$ of those measured at height $95 \mathrm{~cm}$ (Figure 2B).

\section{Performance of the booth with a dummy inside}

The performance of the booth was examined by placing a dummy inside that simulated a medical staff (Figure 2C), and a simple laminar airflow was generated from the FFU. The horizontal airflow velocities at the exit of the booth $(\mathrm{Vy})$ were measured at various heights ranging from 40 

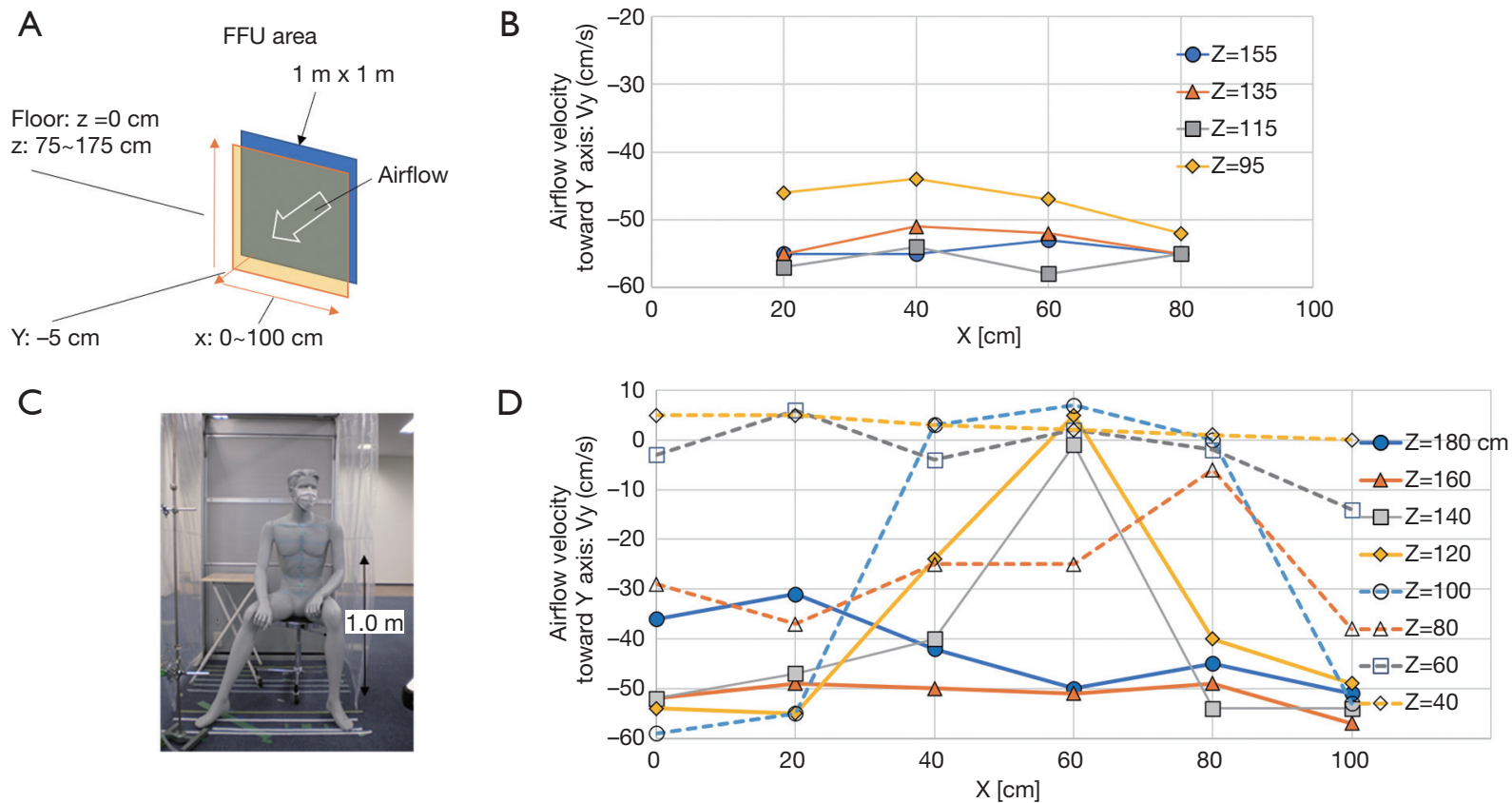

Figure 2 Performance of the FFU used for the booth as a positive pressure machine. The FFU was set at $75-175 \mathrm{~cm}$ above the floor, and the airflow velocities were measured. The dimensions of the FFU area shaped as a square of $1 \mathrm{~m}$, and axes of airflow components horizontal direction (x), toward the FFU (y), and vertical components (z) are shown (A). Airflow velocity from the FFU, Vy (cm/s) at a position $5 \mathrm{~cm}$ apart and heights of 95-155 cm from the floor (B). Image of a dummy sitting on a chair inside the booth (C). Horizontal components of airflow velocities $(\mathrm{Vy})$ at the exit area of the booth with the dummy inside, at heights $40-180 \mathrm{~cm}$ from the floor (D). FFU, fan-HEPA filterunit.

to $180 \mathrm{~cm}$ from the floor $(\mathrm{Z})$ and from 0 to $100 \mathrm{~cm}$ from the left end of the FFU $(\mathrm{X})$. It was found that the flow velocities at a height of 120 to $140 \mathrm{~cm}$ from the floor were suppressed mainly at $40-80 \mathrm{~cm}$ of $\mathrm{X}$ axis, probably because the airflow was blocked by the dummy (Figure 2D). Vertical and horizontal airflow velocities were measured just in front of the dummy's chest below the chin, an area of $40 \mathrm{~cm} \times 40 \mathrm{~cm}$ (Figure 3A). It was apparent that the airflow at the center of $x$-axis lost horizontal velocity, gained vertical velocity and flew up to the chin (Figure $3 B, C$ ) because an air turbulence occurred in front of the dummy's chest by blocking the airflow from the backside, as was confirmed by a video image that recorded the airflow there using smoke generated in front of the dummy (Video 1). With this turbulence, the cigarette smoke particles sent by a cough from outside the booth, simulating bio-particles of cough, reached the face area of the dummy (Video 2), suggesting that the simple laminar flow from the FFU could not push back the cough particles. Moreover, it seemed rather dangerous that particles moved up to the face area, and it was necessary to find a way to prevent it and efficiently push back the cough.

\section{An addition of a front curtain and positioning of the dummy}

To improve the situation, we added a short curtain to tighten the airflow and get a stronger flow. At first, a simple, straight-cut curtain of a length of $940 \mathrm{~cm}$ was draped from the roof to a height one meter from the floor, and airflow in front of the dummy sitting at an angle $90^{\circ}$ about $50 \mathrm{~cm}$ from the FFU (Figure S3A), apparently blocking the stream, was analyzed. Vertically, the velocity of the airflow at the center of the $\mathrm{x}$-axis was improved, but those at both sides of the axis were not, and in addition, the horizontal velocities still went backward and did not improve particularly at the central part (Figure 4A). Next, we changed the position of the dummy to be placed at some angle to the airstream line to make the stream smooth. The vertical velocity of the airflow improved significantly with the angle $45^{\circ}$, although it was still not improved horizontally (Figure 4B). With this system, the air velocities at the exit site of the booth were measured and the acquired velocities were found to be 

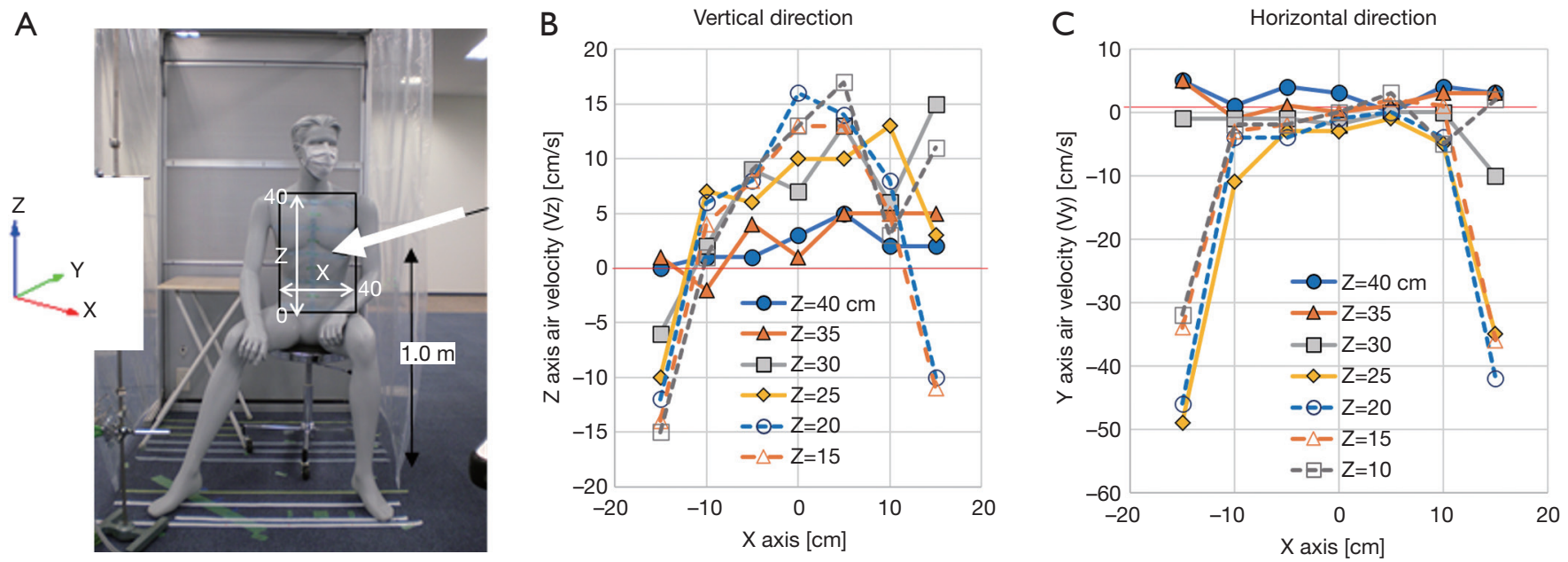

Figure 3 An airflow in front of a dummy's chest without a front curtain. The black square and the white arrow indicate the targeted area $(40 \mathrm{~cm} \times 40 \mathrm{~cm}$ ) for measurement at every $5 \mathrm{~cm}$ from the dummy's thigh (about $60 \mathrm{~cm}$ from the floor) to below the chin (A); the airflow velocities of the vertical component, $\mathrm{Vz}(\mathrm{B})$, and horizontal component, $\mathrm{Vy}(\mathrm{C})$ of the airflow at the targeted area. The bold white arrow indicates an area of the dummy for analyses for the graphs of (B) and (C).

almost the same with those of the booth without the front curtain, which was about $55 \mathrm{~cm} / \mathrm{s}$. It was not expected to be enough to overcome the airflow of the human cough, which was estimated by aerodynamic analyses on a cough of an adult Male volunteer to have a velocity of about $0.5 \mathrm{~m} / \mathrm{s}$ at $30 \mathrm{~cm}$ distance from the mouth (23), and needed improvement.

To acquire a stronger airstream at the exit site, we tightened the airstream some more. For this purpose, the front curtain was changed to a stair-cut shape, in which a small square sheet $(50 \mathrm{~cm} \mathrm{~W} \times 40 \mathrm{~cm} \mathrm{H})$ was added to the half side of the straight curtain (Figure $5 A$ ). With this version, both the vertical and horizontal air velocities at the dummy's chest did not improve from the last two versions, but the air velocity at the exit site improved significantly to about $60 \mathrm{~cm} / \mathrm{s}$. However, it was not improved when the stair part was lengthened to $95 \mathrm{~cm} \mathrm{H}$ with almost unchanged results (Figure 5B). Therefore, we adopt the former design of the stair-cut hereafter.

Here, a target airflow velocity at the exit site of the booth was assumed to be more than $30 \mathrm{~cm} / \mathrm{s}$ to push back the movement of the bio-particles in the cough. Our previous data of an adult male volunteer's cough suggested that the velocity of cough particles lost the horizontal movement at $40 \mathrm{~cm}$ from the mouth and moved only with the insensible environmental air movement with a velocity of $20-30 \mathrm{~cm} / \mathrm{s}$ at maximum even under calm conditions (23). The velocity of the airflow that went out from the booth was measured. It was about $5-25 \mathrm{~cm} / \mathrm{s}$ with the straight-cut curtain at center and close to the curtain end (Figure 6A), but it was improved to $30-75 \mathrm{~cm} / \mathrm{s}$ with the stair-cut curtain (Figure $6 B$ ). The latter met the targeted velocity but the former could not.

With the latter version, the flow from the FFU did not make a turbulence in front of the chest (Video 3). It can efficiently wash out cough particles, even if they enter into the booth being carried by a stronger cough's flow. When a man coughed after smoking one breath of cigarette at the booth before the front curtain, a large amount of smoke entered in the booth but it was washed out efficiently and the count of particles derived from the cigarette smoke was zero at the face area of a dummy sitting inside the booth, as well as that of a dummy in a standing position (Video 4) while the machine was switched on. On the other hand, the smoke particles filled the booth immediately after switching off and the particles increased to over the detection limit (no video image).

\section{Negative pressure machine use}

In addition to the development of the positive pressure booth machine, the booth was also designed to be used as a negative pressure booth system to isolate a patient to protect a staff examining the patient (Figure $S 2$ ).

At first, the booth without the front curtain was tried. The man in the booth coughed toward the dummy doctor sitting outside the booth in front of him while the machine was switched on (Figure S3, B1), and a very high number of particles that reached the dummy's face area was recorded 


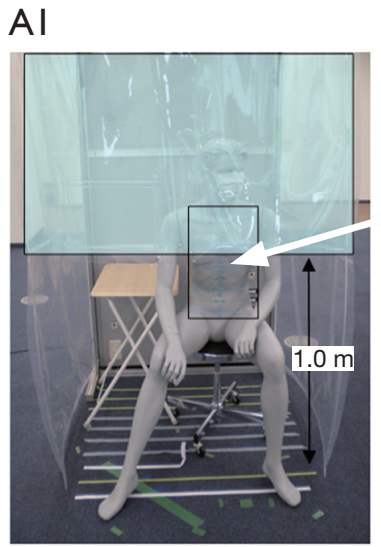

BI

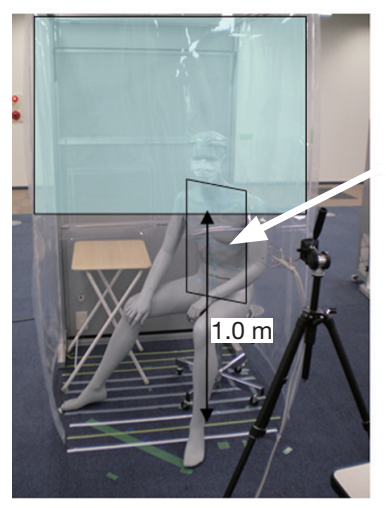

A2

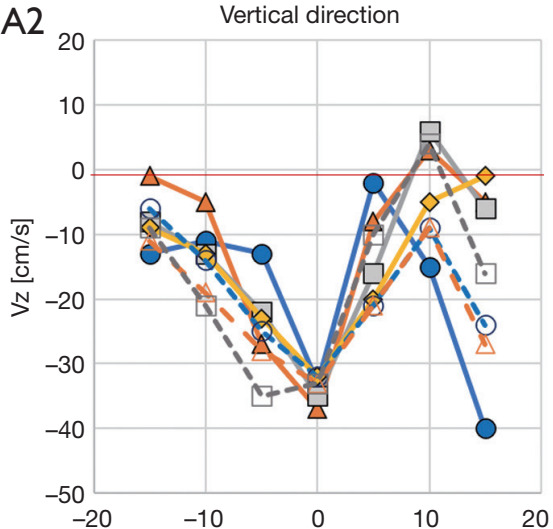

B2 20
10

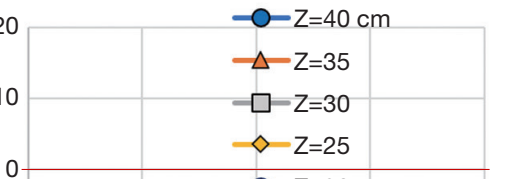

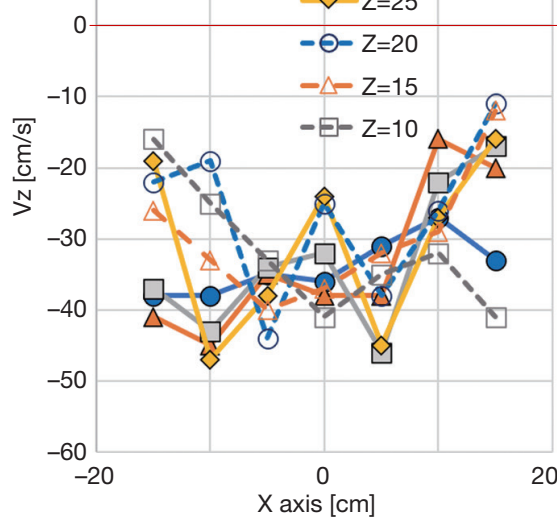

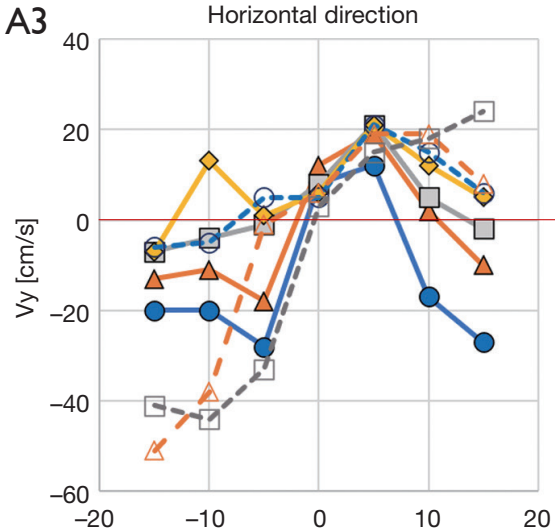

B3 30

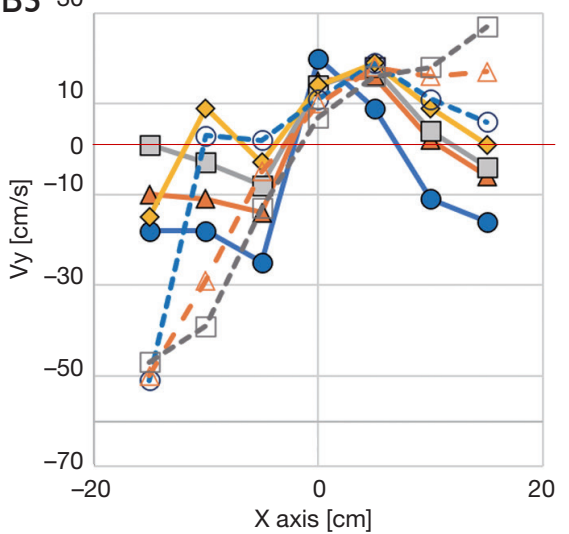

Figure 4 An addition of a straight-cut front curtain. A straight-cut curtain of length $940 \mathrm{~cm}$ was draped from the roof to a height one meter from the floor, and the airflow in front of dummy's chest was analyzed. The dummy was set facing straight to the exit (A1). The dummy was set at an angle $45^{\circ}$ to the airstream line (B1). The vertical velocity, Vz (A2) and the horizontal velocity, Vy (A3), with the straight-facing position of the dummy, and $\mathrm{Vz}$ and $\mathrm{Vy}$, with the dummy's positioning at an angle $45^{\circ}$ to the airstream (B2,B3, respectively). The white arrows indicate areas of the dummy for analyses for the graphs of (A2, A3) and (B2, B3).

(Video 5), which meant the possible exposure to pathogens in practical settings. Thus, we adopted the front curtain to the negative pressure machine, same with the positive pressure use.

Both a dummy doctor set outside the booth at $40 \mathrm{~cm}$ from the front curtain and a man inside the booth were positioned at an angle $45^{\circ}$ to the air stream line to make the stream from outside to the FFU smooth (Figure S3, B2). The airflow velocities at the entrance of the booth were compared between versions with straight-cut and staircut front curtains. As a result, the velocity of the former was about $40 \mathrm{~cm} / \mathrm{s}$ and that of the latter was about $70 \mathrm{~cm} / \mathrm{s}$ (Figure 6C,D). Thus, the stair-cut front curtain was adopted to the negative pressure use as well.

With this system, the laminar airflow from the outside entered into the booth smoothly (Video S1) and the particle number at the face of the dummy doctor was recorded as zero for the cough from a man inside sitting at $30 \mathrm{~cm}$ distant from the front curtain directed at the dummy doctor sitting outside, as well as that at a dummy in a standing position (Video 6), suggesting no exposure to any pathogen in the cough.

The negative pressure booth machine was designed to be applied also for examination of a patient who is lying on a stretcher (Figure $S 4 A$ ). For this, a flapped window of size $70 \mathrm{~cm} \times 35 \mathrm{~cm}$ was placed on the side curtain walls. The airflow velocities measured at the window were about 50 
Al

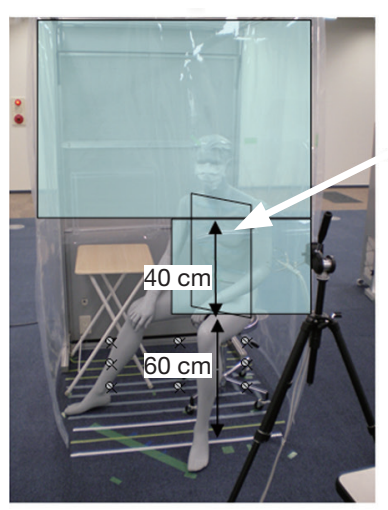

B I

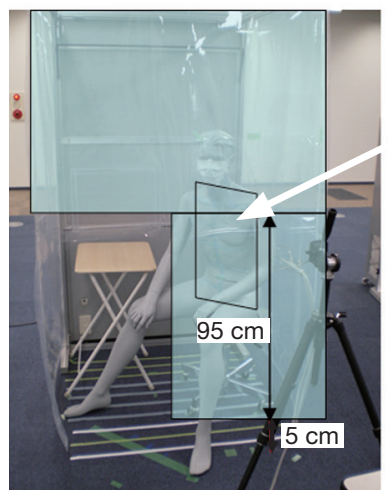

A2

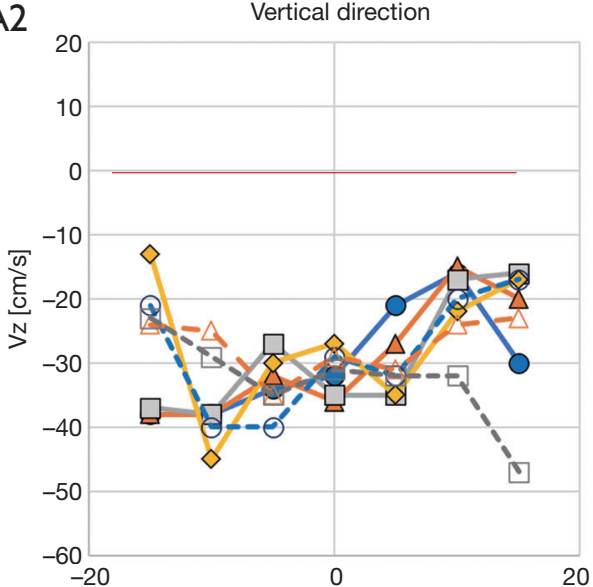

B2

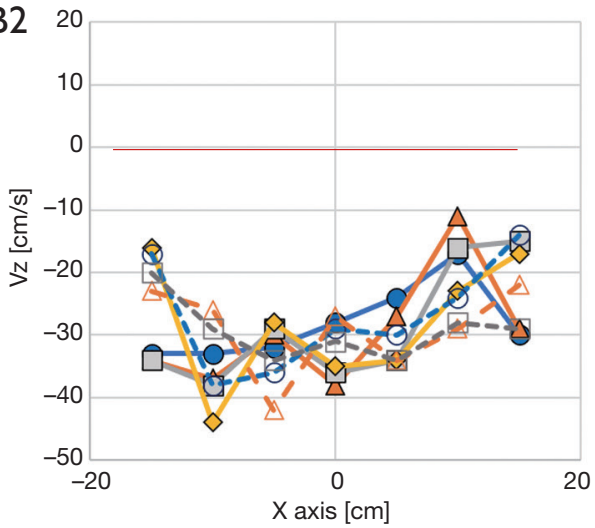

A3

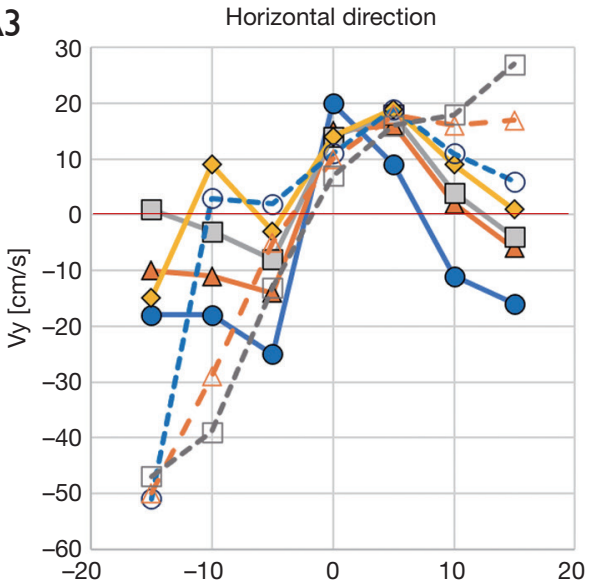

B3

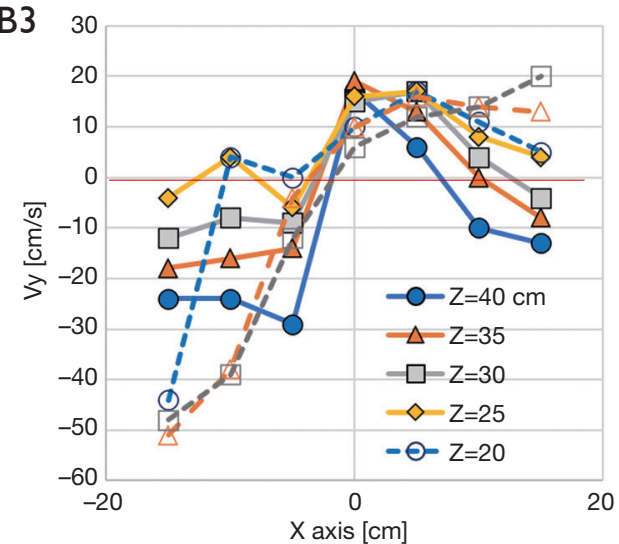

Figure 5 An addition of a stair-cut front curtain. With a stair-cut curtain, the airflow in front of the dummy's chest was analyzed, with the dummy being set at an angle $45^{\circ}$ to the airstream. With the curtain with halves of length $940 \mathrm{~cm}$ and $+40 \mathrm{~cm}$ draped from the roof (to the height one meter and $60 \mathrm{~cm}$, respectively, from the floor) (A1), with the curtain with halves of length $940 \mathrm{~cm}$ and $+95 \mathrm{~cm}$ (B1). The vertical velocity, $\mathrm{Vz}$ (A2) and the horizontal velocity, $\mathrm{Vy}$ (A3) with the curtain length $940 \mathrm{~cm}$ and $+40 \mathrm{~cm}$, and $\mathrm{Vz}$ and $\mathrm{Vy}$, with length $940 \mathrm{~cm}$ and $+95 \mathrm{~cm}$ (B2,B3, respectively). The white arrows are pointing squares in (A1) and (B1), which stand for areas of the dummy for analyses for the graphs of (A2, A3) and (B2, B3), respectively.

$70 \mathrm{~cm} / \mathrm{s}$, more than enough the flow velocity requirement of $30 \mathrm{~cm} / \mathrm{s}$ (Figure 7). The leakage of the cough particles of a volunteer on a stretcher was measured. The particle count at the face area of the dummy doctor standing $20 \mathrm{~cm}$ distant from the side window was zero in the air sampled at the face of the dummy doctor (Video S2). It was supported by an additional experiment in which cough particles were substituted with cigarette smoke as was done in the experiments for the positive pressure use. A volunteer lying on the stretcher coughed after one inhalation of cigarette smoke while the machine was switched on. The leak of smoke particles through the opened side window was almost none immediately after coughing at a position outside the booth and $5 \mathrm{~cm}$ distant from the opened window, whereas the particle count there became about 46,000/L immediately after it was switched off. Thus, a physician can examine the patient through the window, without direct exposure to airborne pathogens from the patients (Figure S4B).

The side window was designed so that a physician can perform through it medical practices that frequently generate aerosols and bear a great infection risk like tracheal intubation to or suctioning (16) from a patient on a stretcher wheeled through a curtain on the other side of the booth (Video S3) without exposure to the aerosols.

\section{The acceptable flowrate}

The initial flow rate of the FFU was the highest one 

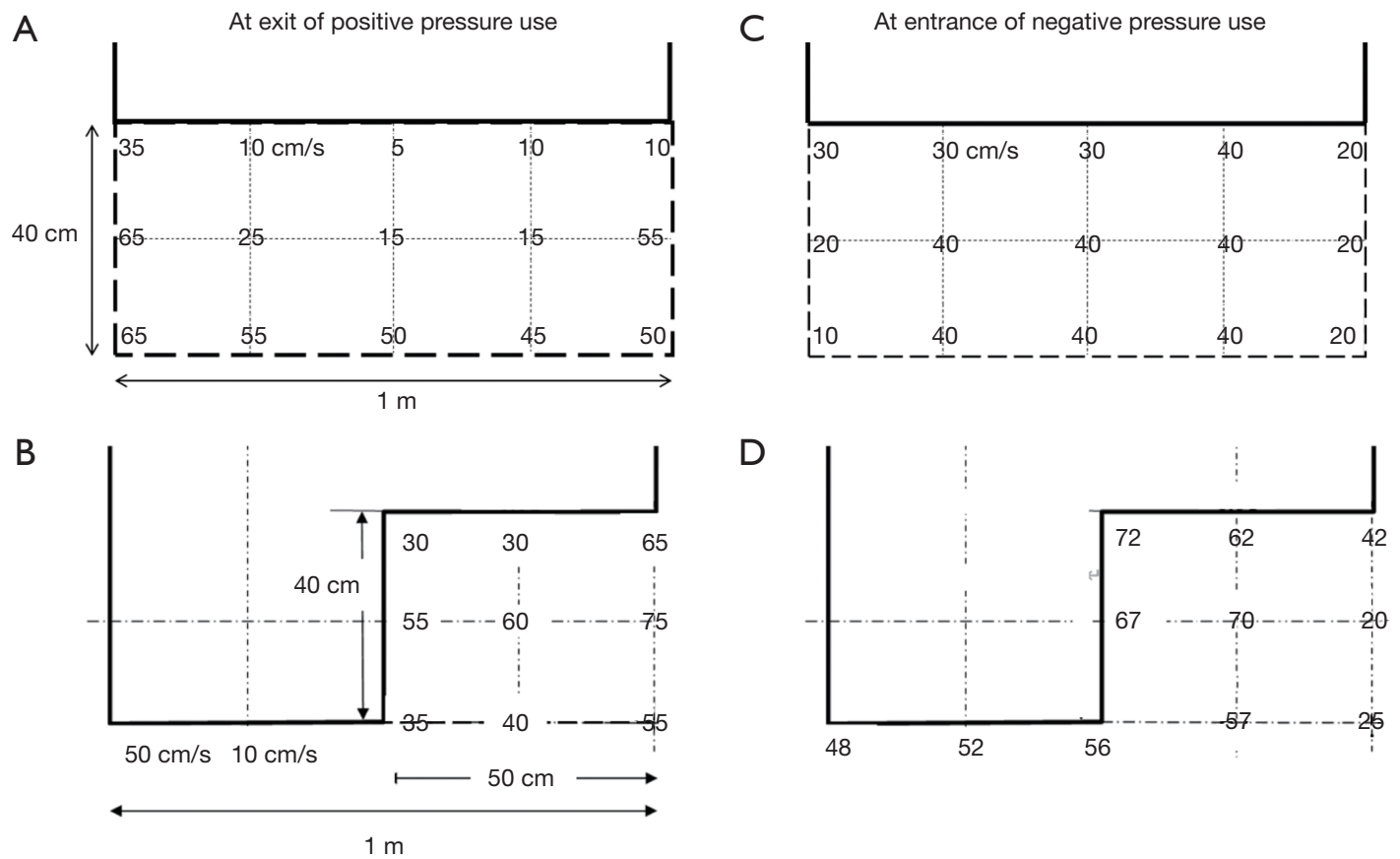

Figure 6 Air velocities at points below the front curtain. Below the straight-cut (A) and stair-cut (B) curtains at the booth exit of positive pressure use, and the straight-cut (C) and stair-cut (D) curtains at the booth entrance of negative pressure use.

available at the time, $30 \mathrm{~m}^{3} / \mathrm{min}$. We tried to find a range of acceptable airflow rate of the FFU for a good performance of Barriflow ${ }^{\circledR}$, which can counteract against the airflow of a cough from outside the booth. The flowrate was changed in a stepwise manner and an experiment was performed with each flowrate, to know whether leaking occurs at the inside or outside the booth, using smoke which is coughed by a volunteer sitting outside or inside the booth in both the positive and negative pressure uses, respectively. The air was sampled for measuring the particle concentration at the dummy's face in positive pressure use and near the opening area just below the front curtain in negative pressure use.

The flow rate of the FFU was lowered by reducing the rotating speed of the fan of FFU using an inverter. The leaked smoke started to appear after $25 \mathrm{~m}^{3} / \mathrm{min}$ and reached the limit of the counter at about $20 \mathrm{~m}^{3}$. Thus, we concluded that airflow should not be lower than $25 \mathrm{~m}^{3}$ and the flowrate was fixed to $30 \mathrm{~m}^{3}$, the original flowrate of the FFU, taking a safety margin from $25 \mathrm{~m}^{3}$ to avoid a risk of aerosol infection by a patient's cough.

\section{Discussion}

The booth system named Barriflow ${ }^{\circledR}$ is reasonable for use

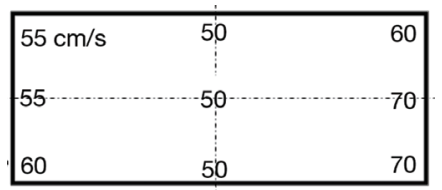

Figure 7 Air velocities at several points in the opened side window in the negative pressure use.

in the medical practice due to several improvements from a simple FFU acquired through aerodynamically solid tests. It would be able to provide safety to the medical staff who examine patients with contagious respiratory diseases in medical settings, like out-patient special clinics for emerged diseases or emergency rooms. In addition, it would be able to provide the staff a relief from stress; otherwise, they would be forced to wear heavy-duty protection gears for their own safety and to keep aware of maintaining their fitness at all times.

The booth was designed to counteract coughs but has a limitation in terms of power of the airflow generated by the FFU due to its own fixed air flow rate. Therefore, it cannot counteract a sneeze, of which air velocity is more than $10 \mathrm{~m} / \mathrm{s}$ at $50 \mathrm{~cm}$ from the mouth (23), as well as very strong coughs, with much higher airflow than that of the FFU. 
In addition, the sneeze is easily induced during collection of clinical specimens from patients, particularly of nasopharyngeal or pharyngeal swabs. The medical staff may still need precaution and wear protection gears to protect against it. However, the FFU of the Barriflow ${ }^{\circledR}$ has a high performance as an air cleaner with a HEPA filter that filters the air at the rate of $30 \mathrm{~m}^{3} / \mathrm{min}$ and a few minutes will be enough to clean up the total room air if the air volume of the room is not so large. Room air clean-up is an answer to an expected concern that the positive pressure use of the booth may contaminate the outside of the booth and the room where it is placed.

There is another usage of Barriflow ${ }^{\circledR}$ as a powerful FFU. Gynecologists consulted us on a possible case of delivery of a baby from a mother with COVID-19 in a delivery room without any negative pressure system. The breathing of the mother is labored during delivery. Barriflow ${ }^{\circledR}$ 's high performance as an air cleaner with a filtration rate of $30 \mathrm{~m}^{3} / \mathrm{min}$ can make all the air in the small room clean in a few minutes, which is comparable to the air ventilation by opening windows, and provide the staff a safe working environment.

A weak point of the booth is the relatively large noise of the FFU (55-59 dB) inside the booth. However, we hope it can be improved in the future by recent progress in noisereduction fans.

Another weak point is that it does not have a warning system to inform users when the airflow rate becomes low. We use the flowrate of $30 \mathrm{~m}^{3} / \mathrm{min}$ and identified the minimal limit for competency of the booth as $25 \mathrm{~m}^{3} / \mathrm{min}$. Clogging of the HEPA filter from a long-term usage and decrease in the flowrate will pose a risk of aerosol infection through the patient's cough to the medical staff using the booth. The next version of the booth should provide with such a safety system.

The Barriflow ${ }^{\circledR}$ was invented through many steps as reported in this manuscript and some parts of its intellectual property rights are owned by Takasago Thermal Engineering Co., LTD, Tokyo Japan, to which one of the authors (SS) belonged. However, the rights are effective only in domestic Japan, and the know-how to develop it in this paper is generally open. Reproducing a similar product is welcome without concerns for the rights in all countries other than Japan. The authors wish the technology could contribute to infection control in the world.

\section{Acknowledgments}

The authors greatly appreciate useful discussion with the Product Designing Division Takasago Thermal Engineering Co. LTD, for providing us with experimental medical booths. Mr. Suguru Omiya and Dr. Isolde Dapat of the Virus Research Center, Clinical Research Division, Sendai Medical Center for the video files and English editing, respectively.

Funding: Annual research subsidy from Sendai Medical Center, Sendai, Japan.

\section{Footnote}

Data Sharing Statement: Available at http://dx.doi. org/10.21037/jtd-20-1607

Conflicts of Interest: Both authors have completed the ICMJE uniform disclosure form (available at http://dx.doi. org/10.21037/jtd-20-1607). The authors have no conflicts of interest to declare.

Ethical Statement: The authors are accountable for all aspects of the work in ensuring that questions related to the accuracy or integrity of any part of the work are appropriately investigated and resolved.

Open Access Statement: This is an Open Access article distributed in accordance with the Creative Commons Attribution-NonCommercial-NoDerivs 4.0 International License (CC BY-NC-ND 4.0), which permits the noncommercial replication and distribution of the article with the strict proviso that no changes or edits are made and the original work is properly cited (including links to both the formal publication through the relevant DOI and the license). See: https://creativecommons.org/licenses/by-nc-nd/4.0/.

\section{References}

1. Wong BC, Lee N, Li Y, et al. Possible role of aerosol transmission in a hospital outbreak of influenza. Clin Infect Dis 2010;51:1176-83.

2. Yan J, Grantham M, Pantelic JP, et al. Infectious virus in exhaled breath of symptomatic seasonal influenza cases from a college community. Proc Natl Acad Sci U S A 2018;115:1081-6.

3. Leung NH, Zhou J, Chu DK, et al. Quantification of influenza virus RNA in aerosols in patient rooms. PLoS One 2016;11:e0148669.

4. Tellier R. Aerosol transmission of influenza A virus: a review of new studies. J R Soc Interface 2009;Suppl 
6:S783-90.

5. Hatagishi E, Okamoto M, Ohmiya S, et al. Establishment and clinical applications of a portable system for capturing influenza viruses released through coughing. PLoS One 2014;9:e103560.

6. Lindsley WG, Blachere FM, Beezhold DH, et al. Viable influenza A virus in airborne particles expelled during coughs versus exhalations. Influenza Other Respir Viruses 2016;10:404-13.

7. Lindsley WG, Blachere FM, Davis KA, et al. Distribution of airborne influenza virus and respiratory syncytial virus in an urgent care medical clinic. Clin Infect Dis 2010;50:693-8.

8. Blachere FM, Lindsley WG, Pearce TA, et al. Measurement of airborne influenza virus in a hospital emergency department. Clin Infect Dis 2009;48:438-40.

9. Cooper BS, Fang LQ, Zhou JP, et al. Transmission of SARS in three Chinese hospitals. Trop Med Int Health 2009;14 Suppl 1:71-8.

10. Kim KH, Tandi TE, Choi JW, et al. Middle East respiratory syndrome coronavirus (MERS-CoV) outbreak in South Korea, 2015: epidemiology, characteristics and public health implications. J Hosp Infect 2017;95:207-13.

11. Assiri A, McGeer A, Perl TM, et al. Hospital outbreak of middle east respiratory syndrome coronavirus. $\mathrm{N}$ Engl J Med 2013;369:407-16.

12. Wang D, Hu B, Hu C, et al. Clinical characteristics of 138 hospitalized patients with 2019 novel coronavirus-infected pneumonia in Wuhan, China. JAMA 2020;323:1061-9.

13. Li Y, Ning Z, Chen Y, et al. Aerodyamic characteristics and RNA concentration of SARS-CoV-2 aerosol in Wuhan hospital during COVID-19 outbreak. bioRxiv 2020. doi: 10.1101/2020.03.08.982637

14. WHO, influenza, Available online: https://www.who.int/ influenza/human_animal_interface/en/ (Mar 15, 2020).

Cite this article as: Nishimura H, Sakata S. Development of positive/negative pressure booth generating airflow for protection of medical staff from contagious respiratory pathogens. J Thorac Dis 2020;12(9):4633-4642. doi: 10.21037/jtd20-1607
15. WHO Guidelines Approved by the Guidelines Review Committee. Companion Handbook to the WHO Guidelines for the Programmatic Management of Drug-Resistant Tuberculosis. Geneva: World Health Organization; 2014.

16. Simonds AK, Hanak A, Chatwin M, et al. Evaluation of droplet dispersion during non-invasive ventilation, oxygen therapy, nebulizer treatment and chest physiotherapy in clinical practice: implications for management of pandemic influenza and other airborne infections. Health Technol Assess 2010;14:131-72.

17. Milton DK, Fabian MP, Cowling BJ, et al. Influenza virus aerosols in human exhaled breath: particle size, culturability, and effect of surgical masks. PLoS Pathog 2013;9:e1003205.

18. Escombe AR, Oeser CC, Gilman RH, et al. Natural ventilation for the prevention of airborne contagion. PLoS Med 2007;4:e68.

19. Li Y, Leung GM, Tang JW, et al. Role of ventilation in airborne transmission of infectious agents in the built environment - a multidisciplinary systematic review. Indoor Air 2007;17:2-18.

20. Yuen PL, Yam R, Yung R, et al. Fast-track ventilation strategy to cater for pandemic patient isolation surges. J Hosp Infect 2012;81:246-50.

21. Ward M, Siegel JA, Corsi RL. The effectiveness of stand-alone air cleaners for shelter-in-place. Indoor Air 2005;15:127-34.

22. Brosseau L, Ann RB, CDC N95 Respirators and Surgical Masks. Available online: https://blogs.cdc.gov/nioshscience-blog/2009/10/14/n95/. Posted Oct 14, 2009.

23. Nishimura H, Sakata S, Kaga A. A New methodology for studying dynamics of aerosol particles in sneeze and cough using a digital high-vision, high-speed video system and vector analyses. PLoS One 2013;8:e80244. 


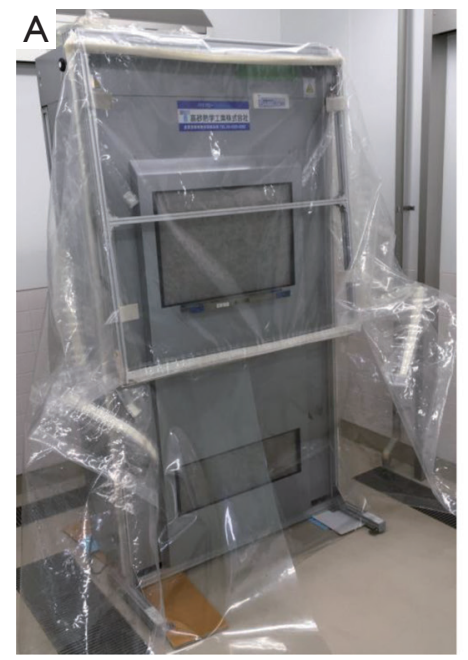

$\mathrm{BI}$

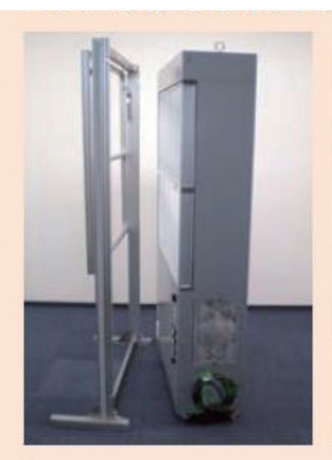

B2

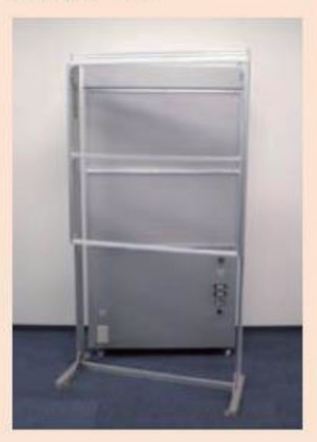

B3

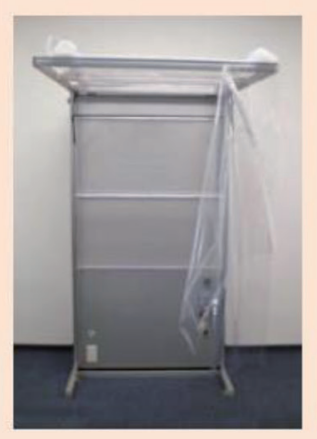

B4

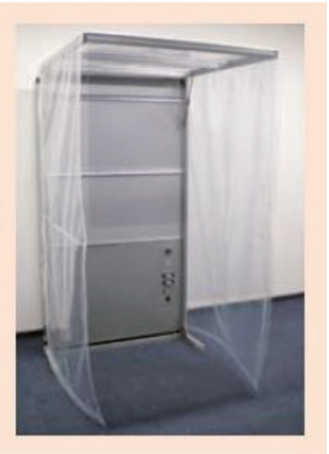

Figure S1 Setting of the booth system. When the ceiling frame is folded down (A). Setting of the hood (B). The frame is attached to the main body (B1). The attaching side depends on the positive or negative pressure use. Folding position before curtains are set (B2). A part of the ceiling frame is unfolded and side curtain walls and a ceiling sheet are set (B3) and just before the front curtain is set (B4).
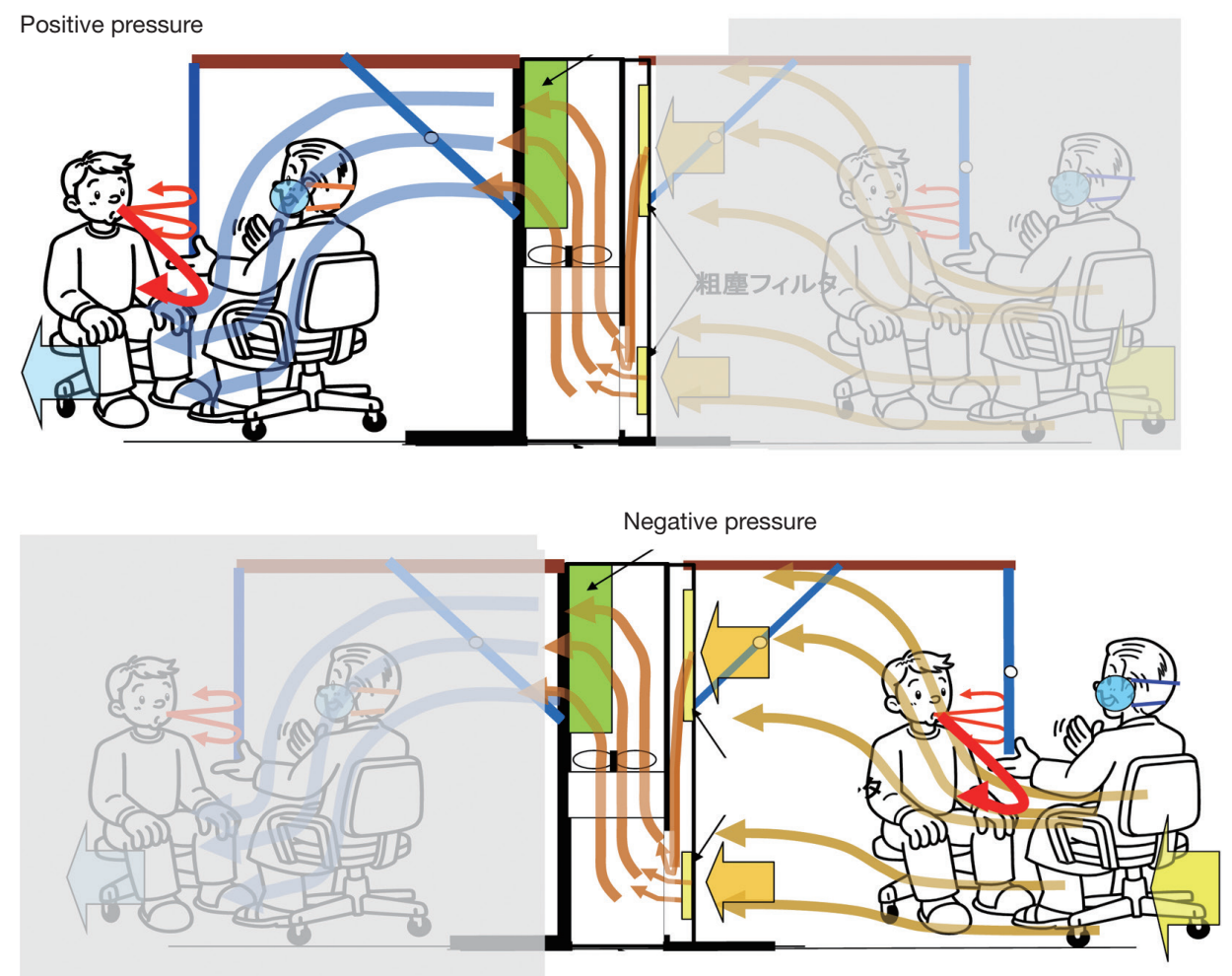

Figure S2 The dual use of the hood as a positive pressure machine and as a negative pressure hood machine. The booth was designed for dual use as a positive and a negative pressure hood machine, by selecting the setting side of the curtain walls for attaching to the booth's main body. 
Without stair-cut front curtain and $45^{\circ}$ positioning

Al

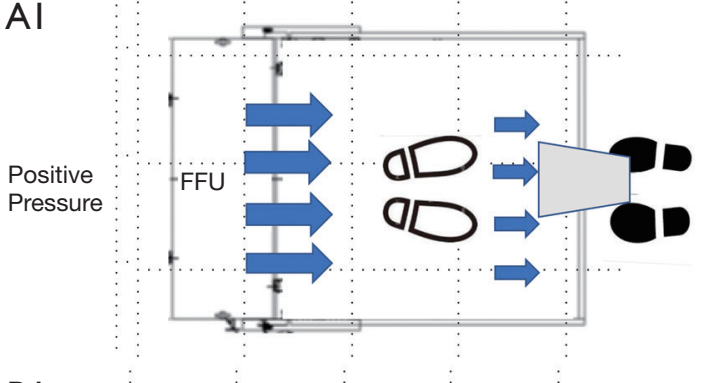

BI

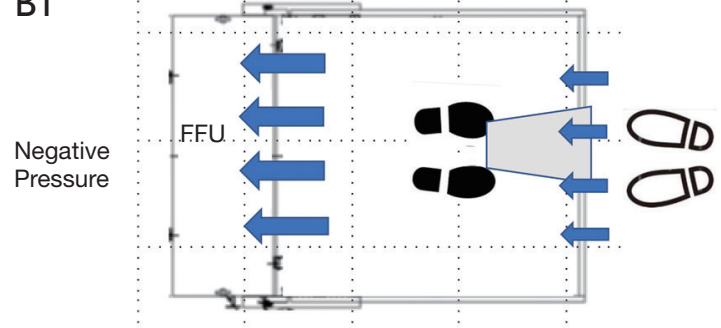

With stair-cut front curtain and $45^{\circ}$ positioning

A2

B2
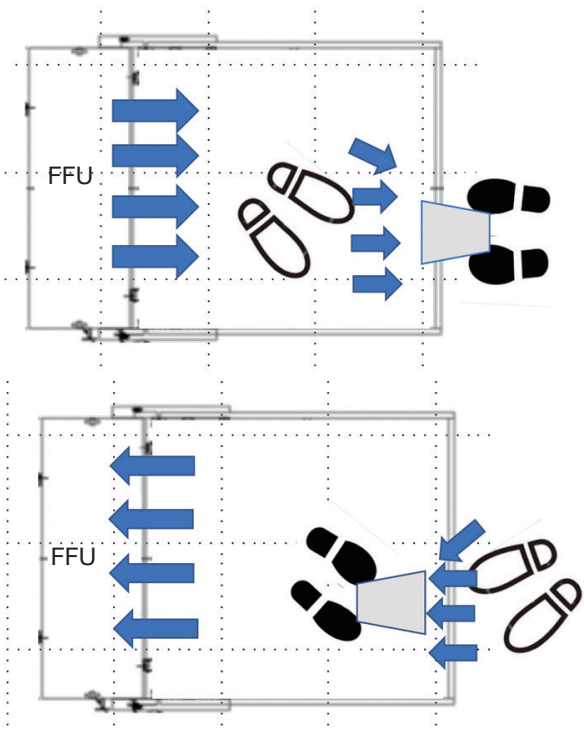

Figure S3 Schematic images of positionings of the dummy doctor and the volunteer patient inside and outside the Barrihood, top views. Settings of the positive pressure use $(\mathrm{A} 1,2)$; the negative pressure use $(\mathrm{B} 1,2)$; without the stair-cut front short curtain and an angle $45^{\circ}$ to the air stream $(\mathrm{A} 1, \mathrm{~B} 1)$ and with it (A2,B2). Arrows: airstreams from/to the FFU. Trapezoidal marks: coughs from volunteer patients. Foot marks show the positioning of the dummy doctor (white) and the volunteer patient (black).

\section{A}

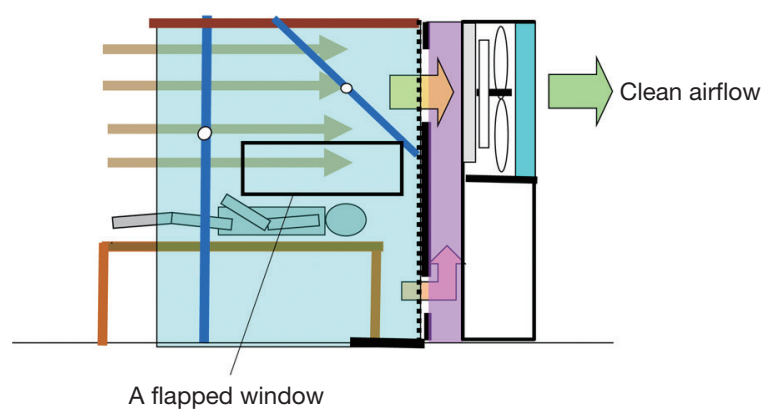

B

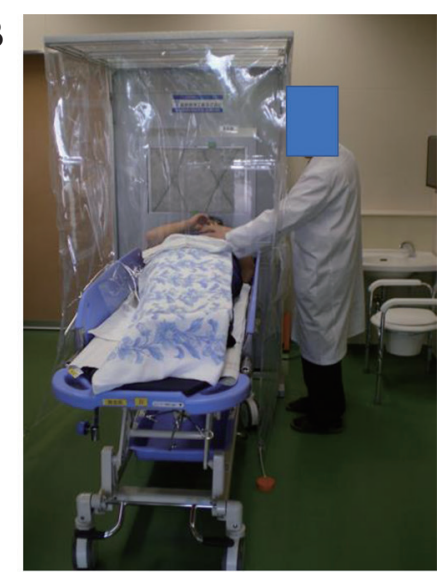

Figure S4 Additional application as a negative pressure booth. (A) A scheme that shows the usage of the negative pressure booth for a patient lying on a stretcher. (B) A picture showing that it is possible for a medical staff to examine a patient on a stretcher through a flapped window in the side curtain wall in the negative pressure booth. 